\title{
Future Scenarios Regarding Tablet Computer Usage in Education and Writing
}

\author{
${\text { Ruhan } \operatorname{Karadag}^{1} \& \text { Bekir Kayabasi }}^{1}$ \\ ${ }^{1}$ Turkish Education, Adiyaman University, Turkey \\ Correspondence: Ruhan Karadag, Turkish Education, Adiyaman University, Turkey. E-mail: \\ rkaradag@adiyaman.edu.tr
}

Received: July 1, 2013 Accepted: September 23, 2013 Online Published: November 29, 2013

doi:10.5539/ass.v9n17p105 URL: http://dx.doi.org/10.5539/ass.v9n17p105

\begin{abstract}
Today, one of the most important sources forcing the educational institutions to alteration is the developments in informatics and communication technologies. Among these alterations, the internet and the tablet computers, which may cause a vital transformation in the history of education, are of importance. Making assumptions, based on today, concerning possible situations in the future and evaluating the reflections of the tablet computers, which have recently left a mark on the education process, on the elementary education process have gained importance. In this study, putting forth the future reflections of the tablet computers on the elementary education process is aimed by means of scenarios and predictions. In the study, how using the tablet computers in educational environment will affect the elementary education and to which extends it will, are focused on and predictions regarding the future was made. Suggestions were given to educators in the light of the findings presented as a result of the study.
\end{abstract}

Keywords: future scenarios, elementary education, tablet PC

\section{Introduction}

The alterations occurring in the world go through a two-way course. On the one hand, these alterations make the lives of the people easy but on the other hand, they threaten the lives of the people. These alterations may be new discoveries and developments or may be alterations threatening our planet and lives; whatever they may be, we have to analyze all the happenings and facts around us well.

Understanding the past and today to understand the future well and analyze it, is not enough. We must be able to estimate the direction and velocity of the change. For this reason, we must learn how to make long-term estimations towards the future and we must form our future instead of accepting what is given to us (Masini, 2002). Thus, we can contribute to awakening of the sensitivity in people towards the tomorrow.

The purpose of the "Future" studies is to alert, arrange, evaluate, support, depict and understand the consciousness and to explain the alternative future models (Bell, 2001). One way to change our understanding towards the future concept is to make a prediction and benefit from the probability studies (Toffler, 1981). When literature is examined, it can be seen that future studies are usually defined with different methods like the Delphi technique, scenario technique and predicting (Cornish, 2004; Gordon, 1992; Wells, 2006). Writing or creating a scenario is a commonly used "future" technique (Stevenson, 2001). Emergence of the scenario technique regarding future studies dates back before the 1950's (Fahey, 1998; Pohl, 1996). The main purpose of the scenarios is to define the existing tendencies and open up the unknown, combine the existentials bound to occur in the future and the unknown (Schoemaker, 1992). Also, scenarios are used in creation process of the alternative futures (Tzu-Ying, 2011) and they help the decision makers in giving a thought to the institutional alterations (Miller, 2006).

With the increase in the awareness towards the future, scenarios regarding the future are written by using the accumulation of the past. Institutions that keep the future in mind write scenarios towards the future in the purpose of taking the societies beyond the industrial era, trying to understand the universe, remain standing and become more powerful, putting forth the threats that may be encountered, preparing for the elusiveness of the future and determining the steps to be taken under the changing circumstances. Future scenarios gain importance in areas like global energy (TUSIAD, 2011), geography (IABA, 2011) and global scenarios (Ogutcu, 2004) in 
our country. As a result of the conducted literature examination, it drew attention that the number of scenarios in the field of education regarding the future is very limited. In the field of the higher education, it is seen that notable scenarios are made withing the scope of the Future of the Higher Education Project (OECD, 2006), the Higher Education Strategy Project (YOK, 2007) and the population and the education (TUSIAD \& UNFPA, 2010) and that the future scenarios are taken into matter (Gultekin, 2006) in education. When investigations regarding the future scenarios carried out in the world are examined, it can be seen that studies including scientific theories, research methods and different training programs regarding the future in the academic and professional fields are realized and that studies concerning the future are given in various lessons and programs. Aside from this, worldwide institutions like World Future Society (WFS) realized various studies regarding the future such as "Communications and the Future: Prospects, Promises, and Problems, The Global Economy: Today, Tomorrow and the Transition, Careers Tomorrow: The Outlook for Work in a Changing World, Frontiers of the 21st Century: Prelude to the New Millennium" (Wells, 2006). Yet, there being no studies regarding the scenarios specifically in elementary education and reading/writing education field in elementary education draws attention.

While owners of the big companies and minds at the top of the government use the scenario planning technique before making important decisions towards the future and develop scenarios that design the model of the different worlds that they'll have to live in, number of scenarios regarding the education process being very low makes us think that we didn't look after our children's future that well.

\section{Education and Future}

Transition process from industrial society to knowledge society obligates realization of important changes in, initially, management and teaching-learning process then teacher-student roles, training programs, learning environment and equipments in the field of education. The information era contributed to the development of the new education technology which renders learning eligible for everyone (Reddi, 1991). This rapid advancement in information technologies pushed the education system into a very fast-paced development and transition process. The world has started to shape the education and education started to shape the world of the future (Davenport \& Davenport, 2001). The information technologies becoming cheap and common sped up the information flow and changed the perceptions regarding time, place and location (Yurdabakan, 2002). Most of the countries that developed or has still been developing in recent years made some innovations to improve their education systems, realized numerous reforms to their education systems and allowed policy and applications to provide modern education equipments (Karip, 1996).

In recent years, all ranks of educational institutions from elementary education to higher education in the world try to improve the knowledge and skill levels of the people by benefiting from the technologies possibilities. Beginning with pens and papers made from different objects, continuing its adventure with blackboard and chalk, giving opportunity to extended education with radio and television and lastly computer, this transition process keeping a light on new discoveries by creating new learning conditions with internet and smartboards acted as a resource for new reforms in the education world.

While the world changes rapidly, to not to fall behind this change, to accord with the speed of the developing technology, Turkey also tried to realize some important projects. Computer classes and education portals were opened within the context of spreading the usage of technology in education and schools, computer education was given to teachers and support campaigns were organized for education with computers. Conducted studies regarding all ranks of education system were carried out to provide the usage and extensification of new technologies in education and to make teachers and students use information technologies tools as a means at every lesson (Microsoft Life, 2005-2006). A project was realized in recent years to establish an internet network topology involving all the classes in Turkey and to make all the elements partaking in the education ecosystem share interactive information by easily connecting to each other through this network (students, teachers, training course managers, parents and etc.), and approximately 12 thousand tablet computers were aimed to be distributed in 2011-2012 school year withing the scope of this project.

Transition from blackboard that has a very long history in terms of use, to computer-supported education carries a notion of change and maybe a nation of transformation. Yet, like there are positive effects of every change and transformation; there are also negative effects. For this reason, these changes that were gone through in education process require entering an era in which new beginnings are questioned. This questioning will make the possible results this process will create be comprehended better, also it will contribute to probable inclinations that may occur later be understood better. In this regard, projections towards the future regarding the tablet pc usage in education need to be put forth explicitly. For scenarios give opportunities to the modelling of 
the uncertainties concerning the future, benefiting from this technique perceptibly in creating estimations towards the future regarding the tablet pc usage in education process is possible.

This research aims to discuss, based on scenarios, the probable reflections and tendencies of tablet computers, one of the educational technologies which are a product of the important changes occurred in the education process, regarding their usage in the elementary education. To this end, this study was structured on the basis of emphases and references for scenarios regarding the future in the event of using the tablet computers in elementary education.

\subsection{The Dramatic End of the Pen}

Almost five thousand years passed from the time that first symbols were written on clay tablets, which were dried in the sun, with objects that look-alike pen till today. Experts named this complex symbols system, which was developed by Sumerians, as cuneiform. Name symbols given to the writing were used as a dedication to the name of the object that's sculpted on the clay tablet. Pen, in this regard, created the indicator of the object that we remember as one when we say writing, in a sense pen and writing were invented together.

People developed countless languages and as much as alphabets in numerous thousand years. No matter how different these languages and alphabets were, the continuance of all those created languages and alphabets was ensured with pen. During this process, pen became the symbol of both knowledge and virtue. Pen, a part of our written culture, became a silent confidant with which we eternized the thoughts of our brains and mediated the writing to be scraped into the pages of memorableness.

Tablet usage in education will affect the act of writing in elementary education to various extends. During this process, the following statement to occur to mind is inevitable: "We did not create writing, but we can kill the pen." Tablets, which are toys that kids in their read and write age will touch with their fingertips, will kill the pen for the generation that uses tablets.

\subsection{Goodbye to Handwriting}

Handwriting consolidates the reign of pen, leaves personal marks to writing and lastly, it visually favors the contents. For handwriting carries personal marks throughout the world, it's one of the proofs to the identification of a person. In the law literature, the definition of the signature is writing the person's forename and surname with longhand.

Though we have bothers in the matter of reading, writing has always been more bothersome for us. Italic handwriting wasn't in much demand between educated mass for reasons such as published books being used commonly and reading learners consolidating the act of writing by copying the letters in books.

Turkey made a small-scale revolution in our lives by transiting to italic longhand in the school year of 2005. But the italic longhand we are just starting to learn not being used by our teachers yet is such a pity. This technological revolution that's about to start without raising a generation that can't write italic longhand is a sign of proceeding, which will kill handwriting without it even emerging.

Few points of the brain work coordinated during writing. This is a very tiresome process for a kid that's just started to read and write. This process being a habit by not being interrupted and by processing through the circles of knowledge and experience is an obligation. Yet, usage of tablet will destroy the grasping capability of a hand. A kid gaining the ability of doing something with everything he/she touches with his/her fingertips will not be motivated for a struggle that requires ability and experience such as longhand. While writing in tablets, texts without a mistake can be made thanks to the automatic writing controls of the writing programs. Though it'd seem like a good result when looked in terms of the product, it's inevitable that tablet computers will batter the mother-tongue learning to a point from which there'll be no recovery.

\subsection{Disappearance of the Symbolic Value of Writing}

Writing is one of the biggest discoveries of humankind. Writing is just not a discovery that records the sound. Writing is symbolically an extension of our culture. Every letter in the alphabet has a creation adventure. Alphabets carry symbols from the dark ages of the human history. Yet, we can't grasp the importance of writing for we learn it at a very young age. But an ordinary person that knows how to write could be included in a clerk party following the philosophers in human societies dating back before a thousand year.

Our culture evolution showed us that occasionally some positive news may bear some negative results. To wit, the construction of Kagir building killed the woodworking. Though we create building with remarkable magnitudes, it is obvious that we drifted away from the old esthetic tastes. In a sense, we put forth work of arts without art. This situation is the same as the situation of alphabet and writing. The thread of alphabet turning into 
a sequence of computers' infinite sequences from a cultural value created by humans is one of the biggest problems our written culture has faced. The act of writing will able to be executed solely by artificial brain in parallel with the development of tablets. This situation will make people an observer, an onlooker rather than a participant in written culture. Every person will use the same writing type in the same way in tablets. A person will not be able to recognize his/her personal talent; we will end up conducting a creation of erased capabilities formed by only one type of human.

\subsection{Vanishing of the Classic Educational Instruments}

Even though the context of human race's thousands of years' education adventure changed, its form didn't. Tough its context differed; the education system that people shaped includes similar elements from the first formal institution that is, the Eflatun's Academy till today: A place where education is carried out, other people who'll manage and give the education... Pen and similar writing tools, an area where writing will be written... Books, pens, notebooks... A lot of writing materials were used from the clay tablets to papyrus, from gazelle skin to paper throughout the history process. Although there were additions to these fundamentals tools through time, no addition rendered the main education tools useless.

Today's science was gained through the usage of vintage education materials. But, though the usage of tablet computers may seem as a new style that combines book, notebook and pen in itself, the extension of this new education style in our culture isn't evident. Hence, this new style, in which visuality is very intense, can be linked with fun rather than education.

\subsection{Victory of the Visuality}

The language of response and visuality that visual images create in the brain hasn't been solved yet. The possibilities presented by virtual reality builds an imagination world upon the real world. Virtual reality, in a way, puts the dreams of people right beneath their hands. We still couldn't find how to put education into this magical device completely whilst seeing daydreams with computers. Also, how will the effect of virtual reality that drives the people away from the real life and the education that we want to render more understandable by driving people towards the real life get along in the same parallel bares tons of doubts in it.

Though it's without a doubt that it'll be a new opportunity for education, let alone the issue of today's children not being able to concentrate which is one of the most important issues, how to concentrate on education matters with all these numerous attention drawing elements in tablets is a subject we've yet to start thinking on.

Though good directing, studying guidance, struggling provide certain results; it should've been more cold-blooded and more trustworthy about the comeback of this very expensive investing. Just as using an automobile doesn't make us have info about how automobiles are manufactured, everybody using a tablet doesn't necessarily mean that we'll rule the future in terms of computers. The brain creating the virtual reality in computers is possible through penetration to mathematics-logic language. Beginning to use tablet early makes persons only good customers about computers.

Socialization of kids is one the primary objectives of education. The biggest criticism concerning the computers is them confining people into their own worlds and abstractioning them from social life. Social media by no means necessary is the life itself. When anonymous unidentified structure of the virtual world starts to control the students as of the first stages of education age, the fact that they may face isolation from which they may never recover is something not to be ignored.

\subsection{Death of the Memory}

Fundamental components of language and knowledge are indispensable elements we need to comprehend the world. All knowledge we accumulate into our memory is concealed with colors from our cultural life. The knowledge coded in our brains with marks from our society and the environment we live in forms a significant concept for every single person.

Though the level of accumulated knowledge renders the human memory insufficient, fundamental social necessities render human memory necessary to some degree. Yet, the biggest effect of technology is that it rasps our abilities. Transportation possibilities that enable us to reach anywhere easily made excessive weight problem a part of our lives. It's advised for humankind to go back to the life style before technology arrived to get rid of this problem. In this context, easiness to be able to preserve our info that started with a big ease in the memories we carry around will accompany belatedness which will shame the history of humanity in the coming periods. Now, the proponents, whom advised us to benefit from the possibilities of this easy technology, may tell us in the near future, contrary to their customs, to carry a lot of things in our brains. To not do the same mistake all the time, we must not benefit randomly from the easiness which will disable our brains. Emptying our brains doesn't 
necessarily mean that we'll use it better.

Without memory, people we'll raise will not be a member of our own culture. Those people will easily be able to get integrated to other networks with the non-selective attitude of computers that get connected to each other with IP code. This memoryless education may have a supranational goal. This goal will never serve us though.

\subsection{Will a New Tablet Language Be Born?}

Usage of tablets becoming more common and it transiting from a free-will choice to an obligation mean that children, whom didn't complete their language acquisition yet, will face a new language. It'll be more of an acquisition of a language rather than learning. For this reason, new tablet language must be investigated thoroughly and situations that will hinder the development of the language must be eliminated quickly before tablet use. Otherwise, a very negative ground will be set in terms of mother-tongue education. Thousands of terms alongside with tablets will be used intensively during the education process. If we calculate the meanings these terms connotate, we may come face-to-face with results we never could think of.

\section{Conclusions and Discussion}

Modern education researches tell us that brain is not a blank white page, in which we can write everything easily. Tablet computers almost undertaking the entire act of learning may point to losing a few generations with an unplanned initiative. In this new teaching approach, teachers also will not be expected to have enough info about what to do, of course.

With tablet computers started to being used in education life, redoing the definition of education and reconstructing our expectations from education seem inevitable. Tablet computer is just a product but experts, who can't just stop talking about the disadvantages of using a phone during class, keeping a silent mouth about use of tablets, which brings freedom to an extend that phones can't be compared to, is peculiar. For tablet will destroy the notion of class.

Because future's world will be very different from today's world, it'll require people with different qualities from today's and time will fall short in preparing the generations of the future. For this reason, big efforts are needed to develop proper goals to meet the necessities. "Good" purpose of education must support the future; "bad" must show resistance against the future. Therefore, educators must determine the elements which will prepare the students to the world of future in the program (Mc Neil, 1985).

When Neil Armstrong first set foot on the moon, he said that "That's one small step for a man, one giant leap for mankind." When education cost of tablet is taken into account, though it seems like a big step, it's a small step in terms of positive results it'll provide. Using tablet computers in education environment will take our written culture that's been formed for thousands of years to a different stage. We don't know how this new change will have effect on our social lives yet. We leave the new generations into the mysterious hands of virtual world during the age of learning reading/writing. Dazzling developments will render estimating what kind of a person they'll be impossible for us. Hence, to not to lose the future generations, to create a more promising future and to elude the negative aspects of tablet computers, keeping some subjects in mind seems obligated:

- We must make children notice that tablets are education tools. Computer is not the life itself, it is a human invention created to ease the life. And students must be brought up with this awareness.

- Knowledge is what is in the mind, not what is in the tablet. No device can replace the human brain. So, educators are required to execute their roles as guides effectively in order to make the students configure information.

- Teachers must be more informed about the tablet usage than the students. They must be teachers between the students and tablet as well.

- Parents being good computer users, they must be the guides of new generations out of school.

- To use the time right and to not get separated from the real life, virtual addictiveness in young generations must be avoided.

- Events of plays and dramas must be increased; fields aside from learning with computers must become appealing.

- To keep the computer addictiveness of young generations under control, events like scouting, which will leave students head to head with the nature, must be used more commonly and productively.

- Usage of internet and social media must get separated, we must be careful against the unidentified world of social media. 


\section{References}

Bell, W. (2001). Futures studies comes of age twenty five years after: The limits to growth. Futures, 33(1), 63-76. http://dx.doi.org/10.1016/S0016-3287(00)00054-9

Cornish, E. (2004). Futuring: The exploration of the future. World Future Society. Bethesda, MD.

Davenport, D., \& Devenport, D. (2001). Future learning: Is it friend or foe. BITIE 2001 Bilişim Teknolojileri Işı̆̆ında Ĕgitim Konferanst ve Sergisi Bildiriler Kitabı. 3-5 Mayıs 2001, Ankara.172-176.

Fahey, L., \& Randall, R. M. (1998). What is scenario learning? In R. Fahey, \& R. M. Randall (Eds.), Learning from the Future: Competitive Foresight Scenarios. Wiley, San Francisco, 3-21.

Gordon, T. (1992). The methods of futures research. Annals of the American Academy of Political and Social Science, 552, 25-35. http://dx.doi.org/10.1177/0002716292522001003

Gultekin, M. (2006). A contemporary issue in education: Future: educational administration. Theory and Practice, 12(45), 61-83.

IABA. (2011). Antalya Mimarlık Bienali (IABA): Batı Antalya için gelecek senaryoları: Kullanım alanından kentsel çevreye. (workshop).

Karip, E. (1996). Etkili eğitim sistemlerinin geliştirilmesi. Ĕ̆itim Yönetimi, 2, 245-247.

Masini, E. B. (2002). A vision of futures studies. Futures, 34(3-4) 249-259. http://dx.doi.org/10.1016/S0016-3287(01)00042-8

Mc Neil, J. D. (1985). Curriculum a comprehensive introduction. Little, Brown an Company.

Microsoft Life. (2006). Eğitimde teknoloji devrimi. Microsoft Life Teknoloji ve Yaşam Kültürü Dergisi. Sayı:29 Aralı 2005 -Ocak Şubat $2006 . \quad$ Retrieved $\quad$ from http://www.microsoft.com/turkiye/mslife/sayi29/kapakKonusu.mspx

Miller, R. (2006). Futures studies, scenarios, and the "possibility-space" approach. Retrieved from http://www.oecd.org/document/63/0,3746,en_36702145_36702265_37627839_1_1_1_1,00.html

OECD. (2006). OECD eğitim müdürlüğü yükseköğretimin geleceği projesi (05 Ekim 2006). Retrieved from http://abdigm.meb.gov.tr/eski_site/uaorgutler/OECD/OECD_YuksekogretimSenaryolar.html

Ogutcu, M. (2004). Küresel senaryolar ve Türkiye için gelecek haritası. Forum İstanbul.

Pohl, F. (1996). Thinking about the future. The Futurist, 30(5), 8-13.

Reddi, U. V. (1991). Sanayi devriminin aşılmast. enformasyon devrimi efsanesi. (Der ve Çev: Y. Kaplan), İstanbul: Rey Yayınları, 345-370.

Schoemaker, P. J. H. (1992). How to link strategic visions to core capabilities. Sloan Management Review, 34(1), 67-81.

Stevenson, T. (2001). The futures of futures studies. Futures, 33(7), 665-669. http://dx.doi.org/10.1016/S0016-3287(01)00009-X

Toffler, A. (1981). Gelecek korkusu: Şok (Translator: S. Sargut). Altın Kitaplar Yayınevi.

TUSIAD. (2011). Küresel enerji stratejileri simülasyonu:Türkiye'nin gelecek 10 yılı (6 Ekim 2011). Retrieved from http://www.tusiad.org/etkilesim/video-galeri/kuresel-enerji-stratejileri-simulasyonu-turkiyenin-gelecek-10-y ili/

TUSIAD., \& UNFPA. (2010). 2050'ye doğru nüfusbilim ve yönetim: eğitim sistemine bakış (5 Kasım 2010). Retrieved from http://www.tsv2023.org/pdf/2050_dogru_yansimalar.pdf

Tzu-Ying, W. (2011). Learning English in Taiwan's elementary schools. Journal of Futures Studies, 16(2), 35-46.

Wells, H. G. (2006). The origins, history, and nature of future studies. The subject matter, goals, and methods of future studies. Retrieved from http://centerforfutureconsciousness.com/pdf_files/Readings/FutureStudies.pdf

YOK. (2007). Türkiye’nin yükseköğretim stratejisi. Ankara: Meteksan A.Ş. Yayın No: 2007-1.

Yurdabakan, I. (2002). Küreselleşme konusundaki yaklaşımlar ve eğitim. Eğitim Araştırmaları, 6, 61-64.

\section{Copyrights}

Copyright for this article is retained by the author(s), with first publication rights granted to the journal.

This is an open-access article distributed under the terms and conditions of the Creative Commons Attribution license (http://creativecommons.org/licenses/by/3.0/). 